\title{
Reusing social media information in government
}

\author{
Clayton Wukich ${ }^{\mathrm{a}}$, Ines Mergel ${ }^{\mathrm{b}}$ \\ a Department of Political Science, Sam Houston State University, United States \\ ${ }^{\mathrm{b}}$ Department of Public Administration and International Affairs, Maxwell School of Citizenship and Public Affairs, Syracuse University, United States
}

Keywords:

Reuse of public sector information

Social media content analysis

Social media sharing practices

Twitter

Emergency management

\begin{abstract}
A B S T R A C T
Across policy domains, government agencies evaluate social media content produced by third parties, identify valuable information, and at times reuse information to inform the public. This has the potential to permit a di versity of social media users to be heard in the resulting information networks, but to what extent are agencies relying on private citizens or others outside of the policy domain for message content? In order to examine that question, we analyze the online practices of state level government agencies. Findings demonstrate that agencies emulate offline content reuse strategies by relying predominately on trusted institutional sources rather than new voices, such as private citizens. Those institutional sources predominantly include other government agen cies and nonprofit organizations, and their messages focus mostly on informing and educating the public.
\end{abstract}

\section{Introduction}

Government agencies increasingly monitor, analyze, and interpret social media content produced by other users to understand the public's mood (Zavattaro, French, \& Mohanty, 2015), gain insights from other users (Sutton et al., 2013), and monitor the reach of government curated content. Some of that social media content is then reused and reshared with the public (Mergel, 2013a). This latter practice is impor tant because resharing is oftentimes seen as a tacit endorsement of an online actor and a confirmation of the trustworthiness of its content, which potentially raises the profile of the account from which informa tion is shared. It also has implications on the diversity of actors and ideas in circulation and on who is considered to be relevant within these vir tual conversations (Bruns \& Stieglitz, 2012; Sutton, League, Sellnow, \& Sellnow, 2015).

The existing literature on social media use offers scant evidence, however, regarding what types of accounts and what types of message content government agencies reshare with their followers. This gap is relevant to broader research on social media's effects on public partici pation and interagency collaboration. On the one hand, research dem onstrates that certain government agencies have incorporated tactics to engage citizens (Meijer \& Thaens, 2013; Linders, 2012) as well as other agencies (Sutton et al., 2013). On the other hand, some research highlights the propensity of many agencies to repurpose offline prac tices that are not inclusive of online actors with potentially relevant

E-mail addresses: wukich@shsu.edu (C. Wukich), iamergel@maxwell.syr.edu (I. Mergel). information (Bryer \& Nelson, 2013; Mergel, 2012; Reddick \& Norris, 2013).

Resharing content represents one interactive tactic and warrants at tention. This article examines what social media sources government agencies decide to share, asking whether these actors are new voices such as private citizens and organizations not normally engaged in the policy domain or whether they are established actors (e.g., other institu tions engaged in the policy domain). In order to understand the online practices of government agencies, we chose a specific subset of public managers emergency managers in all U.S. states who are working in incident driven environments and who have to constantly rely on ex ternal information. Findings demonstrate that agencies emulate offline content curating strategies by selecting predominately trusted institu tional sources rather than new voices. Yet at the same time those select ed institutions represent a cross section of agencies working in the policy domain and provide critical pieces of information that if acted upon could empower the public to coproduce household and communi ty safety.

\section{Social media practices in the public sector}

Social media platforms such as the microblogging service Twitter fa cilitate information exchange across a broad array of users (Bruns \& Stieglitz, 2012; Southwell, 2013). Government agencies can use those tools to promote public participation and interagency collaboration; however, their practices differ widely and range from those inclusive of new voices to simple adaptations of offline behavior that fail to gen erate meaningful interaction with others (Mergel, 2012).

Some government agencies implement purposefully inclusive tac tics (Linders, 2012; Meijer \& Thaens, 2013), especially agencies such 
as NASA with their fan based approach to engage diverse audiences in the space sciences or the U.S. Department of Interior with their positive messages about public lands and the emotional appeal of their Instagram photographs. Furthermore, through social media, some gov ernment agencies employ crowdsourcing where an institution "pro poses to a group of individuals of varying knowledge, heterogeneity, and number, via a flexible open call, the voluntary undertaking of a task" (see Estellés Arolas \& González Ladrón de Guevara, 2012, p. 197). These tasks can be related to solving specific problems and/or coproducing a specific good or service (Brabham, 2013). Mergel and DeSouza (2013), for example, detailed how some federal managers in the U.S. employed social media to promote open innovation initiatives. Meijer (2011) pointed out how social media platforms in the Netherlands facilitated coproduction by allowing for citizens to provide experiential information and social emotional support to others.

Not all government agencies implement inclusive strategies, howev er. Mergel (2012) found that instead of interacting with constituents, many agencies in the U.S. federal government repurposed existing press release content and relied on preexisting routines in the form of one way communication strategies. Reddick and Norris (2013) as well as Bryer and Nelson (2013) demonstrated that local government agen cies were not necessarily social via social media either; that is, they did not seek to engage the public in two way conversations but rather posted one way message content.

March (1991) theorized that public sector personnel regularly weigh the costs of exploring and implementing new ideas against the certainty of maintaining existing standard operating procedures. In deed, this tension between exploration and exploitation is present in public administration and has manifested in the past during the imple mentation of various types of information and communication tech nologies (Fountain, 2001; Norris \& Reddick, 2013). Understanding the extent to which agencies implement new ideas as opposed to repurposing existing strategies contributes to our knowledge of social media adoption and use. To differentiate sources of information, we must first, though, identify which sources government personnel con sider to be established and trusted and which are considered to be new voices.

\section{Traditional Information sources and patterns of exchange}

Traditional bureaucratic patterns of information exchange in public administration have long been criticized for their fragmented structures in which information is restricted to a few select actors (Churchman, 1968; Fountain, 2001; Roberts, 2011). This problem is particularly ger mane to emergency management because risk and disasters affect a range of people, organizations, and jurisdictions, and, therefore, re quires information from disparate actors in order to meet the public's needs (Comfort, 2005; Kapucu, 2006).

As a profession, emergency managers have consequently promoted the importance of not just relying on each other for information; they also draw from a variety of other sources. Comfort (2005) illustrated a communication infrastructure in emergency management in which multiple organizations including utility companies, public safety de partments, and others contribute information to a central command center, particularly during large scale incidents. Other sources impor tant to practitioners include meteorologists and seismologists who offer alerts and warnings (Mileti, 1999), engineers and planners (Knowles, 2012) who develop evidence based mitigation strategies, and psychologists and sociologists who illuminate the tendencies of in dividuals during extreme events (McEntire, 2007). There are conse quently an array of information providers that are considered to be trusted sources for government emergency managers.

Public information officers are asked to use those information sources to develop their agency's external message strategies. Their de sired outcome is to create and maintain an accurate set of messages that leads to more informed and effective decision making by other individuals and organizations (Comfort, 2007; Kapucu, 2006; Haddow \& Haddow, 2014). Public information officers have been trained to care fully vet information before they pass it along to the public (Hughes \& Palen, 2012). Inaccurate information (e.g., underestimating the impact of a storm, disseminating incorrect evacuation routes, or promulgating reports regarding incidents that have not actually occurred) can lead people to make suboptimal risk reduction decisions (Lindell \& Perry, 2012). Consequently, emergency managers must be careful not to prop agate unsubstantiated rumors and information.

Still, public information officers and other personnel have the re sponsibility to assess and communicate vital pieces of information. Or ganizations in the field may or may not be in communication with each other (Robinson, Eller, Gall, \& Gerber, 2013) or with members of their own organizations (Butts, Petrescu Prahova, \& Cross, 2007); they may or may not have access to the intelligence created by those coordi nating the emergency operations center (Comfort, 2005; Kapucu, 2006). This creates the problem of information asymmetry in which valuable information exists but is unavailable to all those who need it (Comfort, 2007). To solve this problem, Comfort $(2005,2007)$ and others (Kapucu, 2006; Hu \& Kapucu, 2014; Mendonça, 2007) have ad vocated for expanded access to information and communication tech nologies. Reddick (2011) reported that most state emergency managers considered both Internet based and wireless based technolo gies to be effective. What those designs do not necessarily account for, however, is access for citizens, emergent groups, and organizations out side of the policy domain. Citizens have traditionally contributed infor mation formally through 911 call centers and a structured interview protocol that creates a record of interaction with other agencies. How ever, their access to the resulting intelligence is relegated by intermedi aries such as the traditional news media or the formal press release style information sharing model of government agencies (Tierney, Lindell, \& Perry, 2001). The emergence of social media channels such as Twitter or Facebook, however, offers a means to expand communica tion and interaction with those actors (Hughes, St. Denis, Palen, \& Anderson, 2014; St. Denis, Hughes, \& Palen, 2012).

\section{Social media and emergency management}

Many emergency management agencies use social media to send out information during all phases of the emergency management cycle (e.g., prevention, mitigation, preparedness, response, and recov ery) (Wukich \& Mergel, 2015). This practice was established by the Fed eral Emergency Management Agency (FEMA) as part of their whole community approach to use social media as a linking mechanism to en able a two way dialog between government personnel and the people served (Fugate, 2011). So far, however, empirical evidence shows that government actors' practice is to simply disseminate information and less frequently interact with citizens to advance dialog, diffuse rumors, and/or respond to direct requests (Hughes et al., 2014; Wukich \& Mergel, 2015). Furthermore, Su, Wardell, and Thorkildsen (2013) re ported that most state emergency management agencies fail to system ically monitor citizen information and thereby miss the opportunity to use citizens' knowledge who are considered by FEMA to be the 'first first responders' and possess first hand information from their observa tions of an incident. Consequently, government agencies fail to achieve significant levels of public participation, a frequently espoused goal dur ing the adoption of social media programs (Bryer \& Nelson, 2013; Mergel, 2012). Notable exceptions include certain large scale response operations in which responders directly engaged with constituents (Chatfield, Scholl, \& Brajawidagda, 2013; St. Denis et al., 2012) and the U.S. Geological Survey's “Did You Feel It?" campaign that elicits feedback following seismic activity (Atkinson \& Wald, 2007).

An important problem experienced by emergency managers is that much of the information posted on social media is erroneous (Hughes \& Palen, 2012; Starbird, Maddock, Orand, Achterman, \& Mason, 2014). Unlike traditional communication systems such as 911 , social media 
networks facilitate viral rumor spreading and false information (Starbird et al., 2014). Identifying and correcting false rumors represent key tasks for emergency management personnel (Hughes \& Palen, 2012; Starbird et al., 2014) and can be done manually or through machine assisted tactics (Latonero \& Shklovski, 2011). The concern re garding veracity, therefore, might make personnel reluctant to amplify messages from unknown and untrusted sources.

While agencies may not be aggressively promoting public participa tion, there is some evidence of increased communication with other agencies. For example, Tapia and Moore (2014) reported that agencies tend to use social media "only within their known community and ex tended network" (p. 483). Sutton et al. (2013) illustrated patterns of in teragency communication following the BP Oil Spill in 2010 as many agencies tried to make sense of recovery operations.

Generally, it has become relatively common for government organi zations to passively monitor their colleagues' updates for situational awareness (Kavanaugh et al., 2012; Su et al., 2013; Wukich, 2015) and then forward those messages deemed most valuable to their followers (Hughes et al., 2014). This type of communication supports the mainte nance of a common operating picture in which multiple actors draw rel evant information to inform decision making (see Comfort, 2007). However, little research has been conducted regarding who these con tent providers are, and what type of content they generate via social media.

Based on the existing literature, we assume that emergency man agement agencies likely reshare information via social media on a regu lar basis. Moreover, we assume that that information is derived from traditional government channels as opposed to new voices because public information officers cannot quickly vet the credibility of un known users and the veracity of their messages. To examine these assumptions, we empirically analyze a collection of social media mes sages by emergency managers operating at the state level in the U.S.

\section{Research design}

\subsection{Data collection}

For this research, we collected and analyzed the 8671 tweets from state emergency management agencies over a three month period. In all, agencies retweeted 2986 messages, which accounted for $34.4 \%$ of their entire message content. Our assumption was that the state emer gency management agencies forwarded content they felt to be valuable or interesting enough to share publicly. This can be accomplished through retweeting, a Twitter convention that allows users to forward existing content posted by other users to their followers. This decision to share content represents a validation of sorts and helped us to iden tify content as well as the knowledge producers that government orga nizations deemed as valuable within their network.

State level agencies represent a prudent source of data because gen erally, unlike local governments, they dedicate a number of personnel, as well as resources, to develop their social media capabilities ( $\mathrm{Su}$ et al., 2013). These capabilities provide the basis for careful monitoring and message development practices.

Our data consist of all Twitter content disseminated by state emer gency management agencies in August, September, and October 2013. During this time, a range of large scale incidents occurred including cat astrophic flooding in Colorado, blizzards in North and South Dakota, and the Navy Yard shooting in Washington, DC. Whereas most research on the use of social media in emergency management focuses on a single large scale disaster (Hughes et al., 2014; Sutton et al., 2013), our data al lows us to examine government behavior that spans smaller scale inci dents, periods of calm, as well as large scale incidents. Because of the breadth of the data, we are able to investigate all phases of emergency management (e.g., prevention, mitigation, preparedness, response, and recovery) and all geographic regions in the U.S. This enables us to identify a large information network with a diverse set of actors.
To identify state emergency management agencies' Twitter ac counts, we reviewed each organization's website, which reduced the likelihood of selecting unofficial accounts (see Sutton et al., 2014; Wukich \& Mergel, 2015). Three states, Colorado, Delaware, and Missou ri, advertised two accounts each. For unadvertised accounts, we con ducted Google and Twitter searches. In all, we identified 48 states that maintained a presence on Twitter. ${ }^{1}$

Using those account names as a seed list, we used a scraping pro gram designed by our team to collect all messages from Twitter's appli cation programming interface (API) during our period of observation. Along with timestamps and message content, we collected data on whether the message had been retweeted and, if so, from what account the message originated. Out of the 8671 messages, 2986 were retweets (34.4\%). Forty states retweeted content (mean 74.65; median 20.50; SD 151.88; max 663; min 1). This evidence facilitates the identification of information sources as well as types of message content.

\subsection{Data analysis}

In order to detect who produced valuable content and in what con text they provided that content, we manually assigned attributes to both the accounts retweeted as well as the messages themselves. We identified a total of 725 retweeted accounts and determined whether those accounts belonged to a government agency, a nonprofit organiza tion, a for profit organization, a media outlet, or a private citizen. We broke those categories down further for additional analysis and identi fied different types of government and nonprofit organizations based on organizational mission (e.g., general government, public safety, and others) and geographic scale (e.g., the municipal, county, regional, state, national, and international levels).

Using established typologies of message content (see Sutton et al., 2014; Wukich, 2015), we manually coded each retweeted message to determine whether it conveyed protective action information including warnings and advice; situational information including but not limited to hazard impact; updates on agency operations; guidance related to preparedness activities; or administration related information such as the schedules of executive officials. We also identified the emergency management phase to which the message pertained. For analysis, we used descriptive statistics in the form of frequency distributions and cross tabulations. Additionally, a social network analysis was conducted to determine the extent to which state emergency management agen cies retweeted the same accounts. A one way network was modeled with ties representing state agency retweets. This enabled us to identify a number of accounts that were retweeted by multiple agencies. Our analysis was facilitated using the software package UCINET (Borgatti, Everett, \& Freeman, 2002).

\section{Findings}

\subsection{Types of retweeted Twitter accounts}

During the period of observation, state emergency management agencies retweeted 2986 messages which originated from 725 individ ual Twitter accounts. Table 1 illustrates the frequency distribution of retweeted accounts by type. Government agencies (70.6\%) were retweeted at much higher rates than nonprofits $(10.9 \%)$, news media outlets $(10.5 \%)$, private citizens $(5.8 \%)$, and private sector commercial interests (2.2\%). The sources of information in this network were there fore primarily government agencies.

The preference for other government content is reaffirmed when we examine the frequency distribution of retweets by account type (see Table 2). There was also a preference for nonprofit generated content.

\footnotetext{
${ }^{1}$ Idaho and Pennsylvania did not possess Twitter accounts during our period of obser-
} vation. Alaska had an account, but it was inactive from July 26, 2013 to April 23, 2014. 
Table 1

Frequency distribution of retweeted accounts.

\begin{tabular}{lrc}
\hline & $\mathrm{N}$ & $\%$ \\
\hline Government & 512 & 70.6 \\
Nonprofit & 79 & 10.9 \\
Media & 76 & 10.5 \\
Private citizens & 42 & 5.8 \\
Commercial & 16 & 2.2 \\
Total & 725 & 100 \\
\hline
\end{tabular}

In all, 93.7\% of all retweets originated from a combination of official gov ernment and nonprofit sources. Half of those accounts were retweeted more than once. The average government account, for example, was retweeted 4.76 times (median 2; SD 10.46), and the average nonprofit account was retweeted 4.58 times (median 2; SD 13.39). The two most frequently retweeted accounts over our period of observation were The Great Washington Shakeout (118) and FEMA Region 3 (101) which is located in Philadelphia, Pennsylvania.

These findings support our first assumption which suggests that emergency managers tend to retweet mostly other government generated information (81.6\%). While they retweeted a notable per centage of nonprofit generated information $(12.1 \%)$, those sources were from organizations with long histories of emergency management work, such as the American Red Cross. Consequently, there appears to be a reliance on content from trusted, reliable sources in the form of government agencies and credible nonprofits. State emergency man agement agencies relied less frequently on other types of information providers and rarely shared citizen generated information.

Who were the specific government and nonprofit agencies that state level emergency management agencies relied on for social media content? To better understand the nature of those accounts, we categorized them by organizational mission as well as the geographic scale upon which they operated (e.g., the municipal, county, regional, state, national, and international levels). Table 3 cross tabulates organi zational missions by geographic scale for the different types govern ment accounts.

With respect to government accounts, we observed a range of orga nizational missions. First and most numerous were emergency manage ment agencies (122), which constituted $23.8 \%$ of all actors. They represented municipal, county, regional, state, and national levels of government, although retweeted content, overall, tended to originate from state (33.0\%) and federal (29.3) sources.

Organizations with a focus on meteorology (71) were the second most retweeted type of government agency (13.9\%). These agencies were primarily regional National Weather Service offices that provided alerts and warnings which state emergency management agencies regularly passed along to their own followers. General purpose govern ments (59), particularly at the municipal and county levels, constituted $11.5 \%$ of all government agencies. Those accounts included mainly the official municipal or county Twitter pages for a jurisdiction. Other prev alent types included police, public health, and fire departments all re lated emergency response organizations.

Not all government accounts were agency accounts. Elected officials (24) and executive level personnel also maintained their own official accounts (19). FEMA director Craig Fugate (@CraigAtFEMA) is one ex ample; he was widely retweeted within our period of observation. The

Table 2

Frequency distribution of retweets by account type.

\begin{tabular}{lrrlllll}
\hline & Retweets & $\%$ & Mean & Median & SD & Max & Min \\
\hline Government & 2436 & 81.6 & 4.76 & 2 & 10.46 & 101 & 1 \\
Nonprofit & 362 & 12.1 & 4.58 & 2 & 13.39 & 118 & 1 \\
Media & 100 & 3.4 & 1.32 & 1 & 0.66 & 3 & 1 \\
Private Citizens & 62 & 2.1 & 1.48 & 1 & 2.18 & 15 & 1 \\
Commercial & 26 & 0.9 & 1.63 & 1 & 0.96 & 4 & 1 \\
Total & 2986 & 100 & - & - & - & - & - \\
\hline
\end{tabular}

Table 3

Relationship between type of government and geographic scale.

\begin{tabular}{lrrrrrrr}
\hline & Town & County & Region & State & Nation & Total & $\%$ \\
\hline Emergency management & 18 & 49 & 5 & 29 & 21 & 122 & 23.8 \\
Meteorology & 0 & 0 & 0 & 1 & 70 & 71 & 13.9 \\
General-purpose & 31 & 14 & 1 & 11 & 2 & 59 & 11.5 \\
Police & 11 & 17 & 4 & 17 & 2 & 51 & 10 \\
Public health & 1 & 7 & 0 & 18 & 13 & 39 & 7.6 \\
Fire & 7 & 5 & 5 & 12 & 3 & 32 & 6.3 \\
Parks \& land mgmt. & 1 & 0 & 0 & 10 & 15 & 26 & 5.1 \\
Elected officials & 3 & 1 & 0 & 18 & 2 & 24 & 4.7 \\
Transportation & 0 & 0 & 4 & 17 & 2 & 23 & 4.5 \\
Military & 0 & 0 & 0 & 6 & 6 & 12 & 2.3 \\
Education & 1 & 1 & 4 & 4 & 0 & 10 & 2 \\
Environmental & 1 & 0 & 0 & 7 & 1 & 9 & 1.8 \\
Regulatory & 0 & 0 & 0 & 6 & 2 & 8 & 1.6 \\
Other & 0 & 0 & 0 & 2 & 5 & 7 & 1.4 \\
Earth sciences & 0 & 0 & 0 & 1 & 2 & 3 & 0.6 \\
Information tech. & 0 & 0 & 0 & 3 & 0 & 3 & 0.6 \\
Utilities & 0 & 1 & 0 & 1 & 1 & 3 & 0.6 \\
Agriculture & 0 & 0 & 0 & 2 & 0 & 2 & 0.4 \\
Economic development & 0 & 0 & 0 & 1 & 1 & 2 & 0.4 \\
Homeland security & 0 & 0 & 0 & 1 & 1 & 2 & 0.4 \\
Public works & 1 & 0 & 0 & 1 & 0 & 2 & 0.4 \\
Corrections & 0 & 0 & 0 & 1 & 0 & 1 & 0.2 \\
Housing & 0 & 0 & 0 & 0 & 1 & 1 & 0.2 \\
Total & 75 & 95 & 23 & 169 & 150 & 512 & 100 \\
\hline
\end{tabular}

director's popularity is fitting because he has been an active proponent of social media in emergency management (see Fugate, 2011).

While state emergency management agencies retweeted content from a range of public sector organizations, they tended to retweet non profits with an emergency management mission (65.8\%) such as re gional chapters of the American Red Cross. Other less frequently retweeted sources included animal rescue organizations, volunteer fire departments, and community development organizations.

Table 4 lists the most frequently retweeted accounts from all sources. Some accounts owed their rankings to a relationship with one particular state emergency management agency. Others were widely retweeted across the country. Fourteen of the top 15 accounts were public sector organizations; the one nonprofit organization's mission was to coordinate preparedness exercises with government agencies. Four of the top 15 accounts came from Washington State. During our period of observation, their state emergency management division helped to organize a well publicized earthquake drill which was re ferred to as The Great Washington State Shakeout, and the state agency retweeted a total of 118 shakeout messages. This agency also retweeted the second most content of all other state agencies (628 messages).

Colorado's Division of Homeland Security and Emergency Manage ment retweeted the most content (663 messages). Their focus was in response to catastrophic flooding which occurred throughout much of the state in September 2013. They disseminated content from local

Table 4

Most frequently retweeted accounts.

\begin{tabular}{llll}
\hline Agency & Account & State & Retweets \\
\hline The Great Washington Shakeout & washakeout & WA & 118 \\
FEMA Region 3 & femaregion3 & PA & 101 \\
Ready.Gov & readygov & DC & 99 \\
Citizens Corps & citizen_corps & DC & 92 \\
FEMA Region 8 & femaregion8 & CO & 74 \\
Boulder Office of Emergency Mgmt. & boulderoem & CO & 59 \\
WA Dept. of Natural Resources & wadnr_fire & WA & 55 \\
FEMA & fema & DC & 53 \\
National Hurricane Center & nhc_atlantic & FL & 45 \\
Texas Dept. of Public Safety & txdps & TX & 37 \\
Craig Fugate & craigatfema & DC & 36 \\
WA Health & wa_deptofhealth & WA & 34 \\
WA Natl Guard & wa_natl_guard & WA & 33 \\
CO Dept. of Public Health \& Environment & cdphe & CO & 32
\end{tabular}


level actors (see the Boulder County Office of Emergency Management @boulderoem), state level actors (see the Department of Public Health and Environment @cdphe), and federal level actors (see FEMA Region 8 @femaregion8). Much of Colorado's retweeted content was intended to provide citizens and other responders with an array of response and recovery related information.

Not all accounts were state specific; several top retweeted accounts garnered attention from multiple agencies. Fig. 1 illustrates how state emergency management agencies created a more centralized informa tion network by retweeting the same accounts.

Table 5 presents the most popular accounts. As illustrated in Fig. 1, among the accounts that emergency managers deemed as valuable information providers are FEMA associated accounts which were retweeted by a number of states including: @readygov (17), @fema (14), @citizen_corps (8), @craigatfema (8), @femaregion4 (7), @femaregion8 (6), and @femaregion1 (6). NOAA's account was retweeted by seven states. The National Wildfire Coordinating Group's @inciweb account was retweeted by six state agencies, as was the Cen ter for Disease Control's account (@cdcready). The National Hurricane Center (@nhc_atlantic) also received multistate attention (5) due to their regular hurricane and tropical storm advisories. The fact that these agencies received a notable amount of attention begs the question: what types of content did state emergency management agencies consider valuable enough to retweet?

\subsection{Type of retweeted messages}

If account attributes give us an idea of who the predominant infor mation sources in the network are, message content analysis offers in sight regarding why those particular accounts were considered to be valuable. During our period of observation, state emergency manage ment agencies experienced a range of incidents. Major events included flooding in Colorado, blizzards in the Dakotas, and the Navy Yard shoot ing in Washington DC, all of which prompted the dissemination of pro tective action information. This type of information is designed to
Table 5

Popular Twitter accounts retweeted by state agencies.

\begin{tabular}{ll}
\hline Account & States retweeting \\
\hline readygov & 17 \\
fema & 14 \\
citizen_corps & 8 \\
craigatfema & 7 \\
femaregion4 & 7 \\
femaregion8 & 7 \\
noaa & 7 \\
cdcready & 6 \\
femaregion1 & 6 \\
inciweb & 6 \\
\hline
\end{tabular}

inform individuals of the immediate steps they can take to reduce their levels of risk. Examples include alerts and warnings, advisories, and information on closures, openings, and evacuations. State emergen cy management agencies depended on external content providers for this type of information, including the National Weather Service and local governments. The Colorado Division of Homeland Security and Emergency Management, for example, relied on local governments for information on matters such as evacuations. Boulder, one of the affected communities, provided relevant content:

RT @BoulderOEM: Evacuation ordered: Mouth of Boulder Canyon to Broadway, Pearl to Marine GO TO HIGHER GROUND immediately \#boulderflood.

That retweet offered warning and advice with specific information regarding a mandatory flood evacuation. By retweeting the message, the Colorado agency relayed important information to public officials and other followers which, if read, informed those decision makers' sit uational awareness and ideally drew additional attention to the situa tion. During other incidents across the country, state emergency management agencies retweeted similar content. Additional content

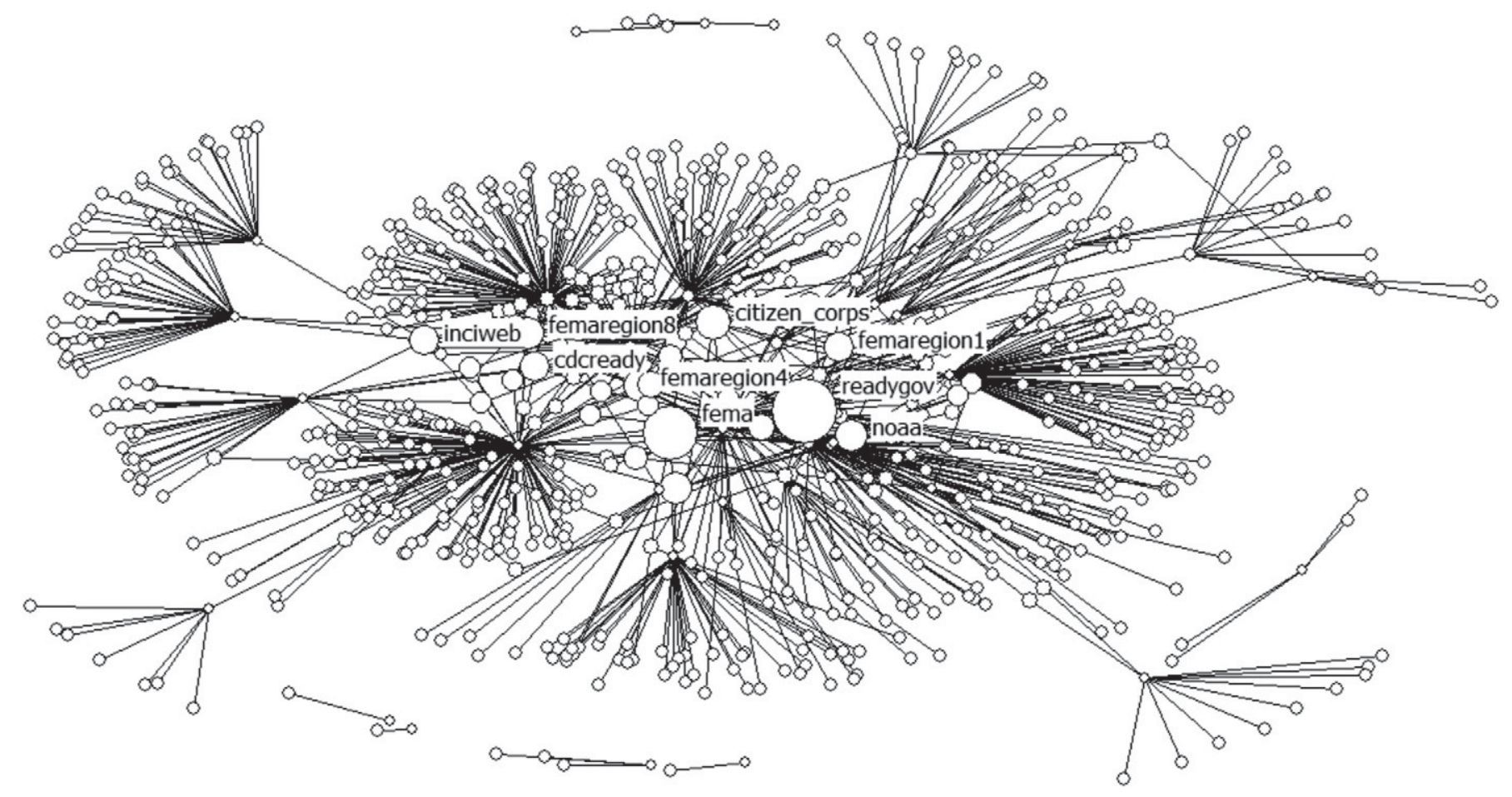

Fig. 1. Network diagram of retweets. 
such as hazard impact and situational information contributed to larger common operating pictures. Following a major October blizzard, South Dakota Emergency Management retweeted a county government orig inated message about Rapid City:

RT @penncoem2: Update: 2 p.m.: With many down trees around the City, citizens have started the process of digging out and...

This message let people know that the town had experienced dam age and was now in the response and initial recovery phases. Messages about specific agency operations were retweeted as well. South Dakota retweeted traditional media content regarding state operations to pub licize their activities to the public:

RT @NewsCenter1: State Moving Quickly to Assess Blizzard Damage with federal shutdown ending.

Not all response related messages, however, were focused on large scale disasters. The vast majority of incidents were relatively low impact storms and traffic accidents. The National Weather Service's regional of fices provided a large quantity of content related to warnings and advi sories. For example, Arizona Emergency Management was one of many agencies that consistently passed along National Weather Service fore casts and advisories:

RT @NWSFlagstaff: Scattered Thunderstorms will impact I 40 be tween \#Winslow and Two guns in the next hour. Slow down for heavy downpours. \#....

Surprisingly, though, response related information was not the most frequently retweeted content. State emergency management agencies were more likely to disseminate preparedness related information intended to educate individuals on how to reduce their risk to various hazards prior to an actual emergency occurring. Table 6 reports the fre quency of retweets by emergency management phase and the average rate at which state emergency management agencies retweeted related content.

Comparatively less attention was given to recovery efforts (11.8\%), although states such as Colorado and South Dakota that experienced large scale incidents relayed important recovery information to citi zens, particularly the availability of federal, state, and local resources. Weld County, Colorado provides one such example:

RT @weldgov: Weld County \#Disaster Recovery Center will open to the public from 8 a.m. 2 p.m. Tues. \#COFlood.

Those types of disaster recovery centers included personnel from federal, state, and local agencies. In addition to recovery messages, many states relayed some administrative oriented messages regarding agency and elected official activities. Fewer states promoted prevention and mitigation activities. Of those messages retweeted, prevention retweets were usually related to structure fires; mitigation retweets promoted flood and other insurance programs.

While an array of organizations and message types were retweeted, the vast majority of messages were derived from government and non profit organizations and pertained to preparedness and response activities.

Table 6

Frequency distribution of retweets by emergency management phase.

\begin{tabular}{lcclllll}
\hline & Retweets & $\%$ & Mean & Median & SD & Max & Min \\
\hline Preparedness & 1155 & 38.7 & 28.88 & 6 & 68.617 & 356 & 0 \\
Response & 1142 & 38.2 & 28.55 & 6 & 56.802 & 283 & 0 \\
Recovery & 352 & 11.8 & 8.8 & 0.5 & 44.572 & 283 & 0 \\
Administrative & 171 & 5.7 & 4.28 & 1 & 12.72 & 78 & 0 \\
Prevention & 129 & 4.3 & 3.22 & 0 & 8.496 & 48 & 0 \\
Mitigation & 37 & 1.2 & 0.93 & 0 & 3.125 & 19 & 0 \\
& 2986 & 100 & - & - & - & - & - \\
\hline
\end{tabular}

\section{Discussion}

Our research examined a specific social media practice of public managers in state emergency management agencies, the resharing of information on the state's official Twitter account from mostly govern ment and nonprofit sector actors. State level agencies served as infor mation curators who identified valuable or interesting content, vetted sources, and relayed content to their followers. While new voices such as citizens' perceptions of the impact of an emergency or their need for support were not emphasized, the expanded information network provided an array of warnings and preparedness tips that if acted upon could empower the public to coproduce household safety and community resilience. These findings contribute to our understanding of how government agencies actually use social media, and reaffirms their reluctance to directly engage new voices (see Bryer \& Nelson, 2013; Mergel, 2012; Reddick \& Norris, 2013).

The practices we investigate are valuable because they confirm the notion that government agencies tend to rely on formal information available in the hierarchy of government itself (see Mergel, 2012; Tapia \& Moore, 2014). Standard operating procedures that were practiced and proven offline are repurposed into online tactics. Hughes and Palen (2012) established that despite the diversity of social media sources, public information officers are still quite careful to ensure the veracity of their agency's posts and are reluctant to promulgate unvetted infor mation. Erroneous information may lead people to make decisions with negative consequences, especially during a disaster. Agencies then are held to account, if not with respect to legal liability (Nicholson, 2007), then in the court of public opinion (Boin, t'Hart, Stern, \& Sundelius, 2005). Even simple mistakes that do not lead to the loss of life and property or any citizen inconvenience may still erode the public's confidence in that agency. Emergency managers, therefore, take pains to ensure the validity of the information they disseminate.

If agencies rely predominantly on the organizations with which they interact outside of social media, what makes our findings relevant? So cial media platforms expand public accessibility to the online govern ment information sharing dynamic. Everyone with Internet access can obtain the information generated and participate in its consumption and vetting, whereas only a limited group of agencies would have had access to this type of information exchange in the past through official and bounded information networks (see Comfort, 2005; Kapucu, 2006). This creates an interagency platform for information exchange, but also a larger community knowledge commons from which many draw on for situational awareness and protective action information; and this begins to fulfill the expectations of researchers with respect to information and communication technology as a means to break down barriers (see Comfort, Boin, \& Demchak, 2010; Fountain, 2001; Ostrom \& Hess, 2007; Roberts, 2011). These online practices expand ac cess to critical pieces of information that empower citizens to coproduce household safety, which in turn contributes to the overall resilience of a community (Wukich, 2013). So while the voices of private citizens and other organizations are not amplified in these networks, the public does benefit from expanded access to the knowledge generated.

\section{Recommendations for practitioners and future research}

Government agencies operating in different policy domains may be more or less inclined to retweet external content. One point for consid eration is the level of risk in which these agencies operate. Agencies op erating in high risk environments may be more apt to incorporate social media into their standard operating procedures; the opportunities to triangulate social media updates from a wide variety of different sources can lead to increased intelligence and support the mission of these orga nizations. Relatedly, differences in organizational culture and the value that organizations place on assessing new information are factors to consider. Agencies that view themselves as the sole information author ity may be less likely to include external information or disseminate 
information from other sources. This might be true for regulatory agen cies that have enforcement functions. Conversely, agencies that offer popular services such as state parks systems may be more inclined to adopt the kind of fan based approach used by NASA and the U.S. Depart ment of the Interior, which actively seeks out and amplifies external content that supports agency operations.

Public managers outside of emergency management are under sim ilar pressure to ensure information veracity may also choose to rely on established, institutional sources. Based on the common characteristics of the source types that we analyze, we would surmise that the follow ing information signals whether a source can be trusted: (a) official ac count status from known public or nonprofit organizations; (b) no known history of posting erroneous information; (c) the demonstration of professional language as opposed to informal commentary; and (d) information relevant to the operations at hand or hazards germane to a relevant jurisdiction.

Our findings are couched in the context that agencies are still devel oping standard operating procedures on how to monitor and release in formation on social media. This article tells an early adopter story. Social media platforms such as Twitter offer non traditional tools with the po tential to increase levels of transparency, public participation and col laboration in government operations (Mergel, 2012). Emergency managers must reconcile these new capabilities with the command and control culture pervasive within their field (Hughes \& Palen, 2012). While we observed some very interactive agencies such as Washington State and Colorado, we also noted that ten states either retweeted nothing or in the case of Alaska, Idaho, and Pennsylvania, actually generated no original content whatsoever. All other states' ac tions ranged in between. This variation, along with the fact that policies governing social media implementation are inchoate across the country (see Mergel, 2013b), justifies further investigation.

We see the need to conduct further research to better understand the operational as well as strategic decisions state emergency manage ment agencies make, or their perceptions about the importance of on line interactions that lead to their online practices observable on social media. For example, we also assume that online retweeting practices depend on who is in the drivers' seat, so to speak. Those public informa tion officers with more experience in using social media as part of their official information sharing strategy might be more prone to retweet content they previously identified as accountable and trustworthy. Other agencies might be lagging behind in their practices or simply do not experience statewide emergencies, so that a need for immediate in formation sharing and monitoring is not a priority.

Another related area ripe for research is how public information of ficers might integrate volunteers or crowdsourcing tactics to collect, vet, confirm, or even create valuable information during incidences since their responses may oftentimes be faster than those of the emergency management agencies. Agencies may not be retweeting content created by private citizens, but that does not mean that they do not have the means to evaluate the information being posted. As an example, virtual operation support teams have emerged who support information col lection and vetting procedures and provide the final results to emergen cy managers. A few outstanding examples are @OregonVOST or @ CanVOST in Canada.

It is important to conduct additional research to understand how vir tual monitoring happens, how the vetted information from social media can be moved into formal decision making processes, and how big data interpretation is then used to deploy resources to the scene. This type of research would also address the (potentially low budget) infrastructure needed to effectively incorporate social media data into existing stan dard operating procedures.

\section{Conclusion}

Social media technologies and especially the public newsfeed on Twitter provide government agencies access to information generated by a range of sources. Government agencies reuse and share some of that information with their own followers. Our analysis demonstrates that government agencies relied on formal information available in the hierarchy of government itself as opposed to new and alternative voices. While government agencies shied away from amplifying private citizens and organizations not regularly involved in the policy domain, they did promote a range of other institutional accounts. The result was the creation of a larger knowledge commons that broke down insti tutional silos and provided organizations and citizens alike with critical pieces of information to coproduce household and community safety. In addition, the retweeted accounts articulated the online network to which government agencies paid attention, and researchers as well as practitioners are able to identify which other organizations government considers as reliable information sources.

Practitioners may be disinclined to retweet content from unknown sources, fearing the promulgation of erroneous information or associat ing their agencies with potentially disreputable individuals. However, the amplification of supportive messages from minimally vetted sources provides a lower risk approach that may engender increased public par ticipation. NASA and the U.S. Department of the Interior have demon strated those tactics via their fan based approach. All agencies, however, especially those operating in high risk environments must ensure the veracity of the messages they choose to share; therefore, the reliance on trusted, institutional sources appears to be safe practice in including external information.

\section{Acknowledgements}

The authors thank Professors Louise K. Comfort, Naim Kapucu, Scott Robinson, and Todd R. La Porte for their helpful feedback at the Public Management Research Conference (PMRC), Minneapolis, Minnesota, June 13, 2015. We are also obliged to the journal's reviewers for their substantive critiques. We thank Dr. Alan Steinberg and Mr. Johnny Nguyen for their work in developing our data collection tool. This pro ject was supported by SHSU's College of Humanities and Social Sciences, the Department of Political Science, and the Center for the Study of Di sasters and Emergency Management.

\section{References}

Atkinson, G. M., \& Wald, D. J. (2007). "Did you feel It?" Intensity data: A surprisingly good measure of earthquake ground motion. Seismological Research Letters, 78(3). 362-368.

Borgatti, S. P., Everett, M. G., \& Freeman, L. C. (2002). Ucinet 6 for Windows: Software for social network analysis. Harvard: Analytic Technologies.

Boin, A., t'Hart, P., Stern, E., \& Sundelius, B. (2005). The Politics of crisis management: Public leadership under pressure. New York: Cambridge University Press.

Brabham, D. C. (2013). The four urban governance problem types suitable for crowdsourcing citizen participation. In C. N. Silva (Ed.), Citizen E-participation in urban governance: Crowdsourcing and collaborative creativity (pp. 50-68). Hershey, PA: IGI Global.

Bruns, A., \& Stieglitz, S. (2012). Quantitative approaches to comparing communication patterns on Twitter. Journal of Technology in Human Services, 30(3-4), 160-185.

Bryer, T., \& Nelson, K. L. (2013). Social media for civic engagement: An exploration of urban governments. In C. N. Silva (Ed.), Citizen E-participation in urban governance: Crowdsourcing and collaborative creativity (pp. 226-246). Hershey, PA: IBI Global.

Butts, C. T., Petrescu-Prahova, M., \& Cross, B. R. (2007). Responder communication networks in the world trade center disaster: Implications for modeling of communication within emergency settings. The Journal of Mathematical Sociology, 31(2), 121-147.

Chatfield, A. T., Scholl, H. J., \& Brajawidagda, U. (2013). Tsunami early warnings via Twitter in government: Net-savvy citizens' co-production of time-critical public information services. Government Information Quarterly, 30(4), 377-386.

Churchman, C. W. (1968). The systems approach. New York: Delacorte Press.

Comfort, L. K. (2005). Risk, security, and disaster management. Annual Review of Political Science, 8, 335-356.

Comfort, L. K. (2007). Crisis Management in hindsight: Cognition, communication, coordination, and control. Public Administration Review, 67(s1), 189-197.

Comfort, L. K., Boin, A., \& Demchak, C. C. (Eds.). (2010). Designing resilience: Preparing for extreme events. Pittsburgh, PA: University of Pittsburgh Press.

Estellés-Arolas, E., \& González-Ladrón-de-Guevara, F. (2012). Towards an integrated crowdsourcing definition. Journal of Information Science, 38(2), 189-200.

Fountain, J. E. (2001). Building the virtual state: Information technology and institutional change. Washington, D.C.: Brookings Institution Press. 
Fugate, C. (2011). Written Statement. Subcommittee hearing: Understanding the power of social media as a communication tool in the aftermath of disasters. U.S. Congress. Senate. Committee on Homeland Security and Governmental Affairs, Subcommittee on Disaster Recovery and Intergovernmental Affairs (111th Cong., 1st sess., 4 May. http://www.hsgac.senate.gov/subcommittees/disaster-recovery-andintergovernmental-affairs/hearings/understanding-the-power-of-social-media-as-acommunications-tool-in-the-aftermath-of-disasters (June 1, 2014)).

Haddow, G. D., \& Haddow, K. (2014). Disaster communications in a changing media world (2nd ed.). Waltham, MA: Butterworth-Heinemann.

Hu, Q., \& Kapucu, N. (2014). Information communication technology utilization for effective emergency management networks. Public Management Review, 1-26.

Hughes, A. L., \& Palen, L. (2012). The evolving role of the public information officer: An examination of social media in emergency management. Journal of Homeland Security \&' Emergency Management, 9(1), 1-20.

Hughes, A. L., St. Denis, L. A., Palen, L., \& Anderson, K. M. (2014). Online public communications by police $\&$ fire services during the 2012 hurricane Sandy. Paper presented at the 2014 international conference on Human Factors in Computing Systems (CHI 2014), New York, NY.

Kapucu, N. (2006). Interagency communication networks during emergencies: Boundary spanners in multiagency coordination. The American Review of Public Administration, 36(2), 207-225.

Kavanaugh, A. L., Fox, E. A., Sheetz, S. D., Yang, S., Li, L. T., Shoemaker, D. J., ... Xie, L. (2012) Social media use by government: From the routine to the critical. Government Information Quarterly, 29(4), 480-491.

Knowles, S. G. (2012). The disaster experts: Mastering risk in modern America. Philadelphia, PA: University of Pennsylvania Press.

Latonero, M., \& Shklovski, I. (2011). Emergency management, Twitter, and social media evangelism. International Journal of Information Systems for Crisis Response and Management (IIISCRAM), 3(4), 1-16.

Lindell, M. K., \& Perry, R. W. (2012). The protective action decision model: Theoretical modifications and additional evidence. Risk Analysis, 32(4), 616-632.

Linders, D. (2012). From e-government to we-government: Defining a typology for citizen coproduction in the age of social media. Government Information Quarterly, 29(4), 446-454.

March, J. G. (1991). Exploration and exploitation in organizational learning. Organization Science, 2(1), 71-87.

Meijer, A. J. (2011). Networked coproduction of public services in virtual communities: From a government-centric to a community approach to public service support. Public Administration Review, 71(4), 598-607.

Meijer, A., \& Thaens, M. (2013). Social media strategies: Understanding the differences between North American police departments. Government Information Quarterly, $30(4), 343-350$

McEntire, D. A. (2007). Disciplines, disasters, and emergency management: The convergence and divergence of concepts, issues and trends from the research literature. Springfield, Ill.: Charles C Thomas.

Mendonça, D. (2007). Decision support for improvisation in response to extreme events. Decision Support Systems, 43(3), 952-967.

Mergel, I. (2012). Social media in the public sector: A guide to participation, collaboration, and transparency in the networked world. San Francisco: Jossey-Bass/Wiley.

Mergel, I. (2013a). A framework for interpreting social media interactions in the public sector. Government Information Quarterly, 30(4), 327-334.

Mergel, I. (2013b). Social media adoption and resulting tactics in the U.S. federal government. Government Information Quarterly, 30(2), 123-130.

Mergel, I., \& Desouza, K. C. (2013). Implementing open innovation in the public sector: The case of Challenge.gov. Public Administration Review, 73(6), 882-890.

Mileti, D. S. (1999). Disasters by design: A reassessment of natural hazards in the United States. Washington, D.C.: Joseph Henry Press.

Nicholson, W. C. (2007). Legal issues. In W. WaughJr., \& K. Tierney (Eds.), Emergency management: Principles and practice for local government (pp. 237-255) (2nd ed.). Washington, DC: ICMA Press.

Norris, D. F., \& Reddick, C. G. (2013). Local E-Government in the United States: Transformation or incremental change? Public Administration Review, 73(1), 165-175.
Ostrom, E \& Hess, C. (2007). A framework for anazlying the knowledge commons. In C. Hess, \& E. Ostrom (Eds.), Understanding knowledge as a commons: From theory to practice (pp. 41-81). Cambridge, MA: MIT Press.

Reddick, C. (2011). Information technology and emergency management: Preparedness and planning in US states. Disasters, 35(1), 45-61.

Reddick, C. G., \& Norris, D. F. (2013). Social media adoption at the American grass roots: Web 2.0 or 1.5? Government Information Quarterly, 30(4), 498-507.

Robinson, S. E., Eller, W. S., Gall, M., \& Gerber, B. J. (2013). The core and periphery of emergency management networks. Public Management Review, 15(3), 344-362.

Roberts, N. C. (2011). Beyond smokestacks and silos: Open-source, web-enabled coordination in organizations and networks. Public Administration Review, 71(5), 677-693.

Southwell, B. G. (2013). Social networks and popular understanding of science and health. Baltimore, MD: The Johns Hopkins University Press.

Starbird, K., Maddock, J., Orand, M., Achterman, P., \& Mason, R. (2014). Rumors, false flags, and digital vigilantes: Misinformation on twitter after the 2013 Boston marathon bombing. Paper presented at the iConference 2014, Newport Beach, CA.

St. Denis, L. A., Hughes, A. L., \& Palen, L. (2012). Trial by fire: The deployment of trusted digital volunteers in the 2011 Shadow Lake Fire. Paper presented at the The 9th International ISCRAM Conference Vancouver, BC, Canada.

Su, Y. S., Wardell, C., III, \& Thorkildsen, Z. (2013). Social media in the emergency management Field: 2012 survey results. Arlington, VA: CNA.

Sutton, J., League, C., Sellnow, T. L., \& Sellnow, D. D. (2015). Terse messaging and public health in the midst of natural disasters: The case of the Boulder floods. Health Communication, 30(2), 135-143.

Sutton, J., Spiro, E., Butts, C., Fitzhugh, S., Johnson, B., \& Greczek, M. (2013). Tweeting the spill: Online informal communications, social networks, and conversational microstructures during the Deepwater Horizon oilspill. International Journal of Information Systems for Crisis Response and Management (IJISCRAM), 5(1), 58-76.

Sutton, J., Spiro, E. S., Johnson, B., Fitzhugh, S., Gibson, B., \& Butts, C. T. (2014). Warning tweets: Serial transmission of messages during the warning phase of a disaster event. Information, Communication \& Society, 17(6), 765-787.

Tapia, A. H., \& Moore, K. (2014). Good enough is good enough: Overcoming disaster response organizations' slow social media data adoption. Computer Supported Cooperative Work, 23(4-6), 483-512.

Tierney, Kathleen J., Lindell, M., \& Perry, R. (2001). Facing the unexpected: Disaster preparedness and response in the United States. Washington, D.C.: Joseph Henry Press.

Wukich, C. (2013). Searching for resilience. Journal of Public Administration Research and Theory, 23(4), 1013-1019.

Wukich, C. (2015). Social media use in emergency management. Journal of Emergency Management, 13(4), 281-295.

Wukich, C., \& Mergel, I. (2015). Closing the citizen-government communication gap: Content, audience, and network analysis of government tweets. Journal of Homeland Security E Emergency Management, 12(3), 707-735.

Zavattaro, S. M., French, P. E., \& Mohanty, S. D. (2015). A sentiment analysis of U.S. local government tweets: The connection between tone and citizen involvement. Government Information Quarterly, 32(3), 333-341.

Clayton Wukich is an assistant professor in the Department of Political Science at Sam Houston State University. Dr. Wukich's research interests include intergovernmental relations and collaborative governance, particularly within the policy domain of disaster and emergency management. His research focuses on how public sector and nonprofit organizations use information and communication technology to increase and improve public participation and interagency collaboration.

Ines Mergel is Associate Professor in the Department of Public Administration and International Affairs at Syracuse University's Maxwell School of Citizenship and Public Affairs. Dr. Mergel's research focuses on the managerial and technological processes in the implementation and institutionalization of innovative public management practices, especially the adoption of new technologies. 